\title{
Teaching during Covid-19: Teacher and Students' Experience
}

\author{
Irtifa Mukhter ${ }^{+*}$ and Dr Richa Chowdhary ${ }^{¥}$
}

\section{Abstract}

On March 2020 most of the educational institutes in India stopped face to face contact with students as a result of countrywide lockdown which was imposed due to COVID-19 pandemic. The impact of the lockdown has affected the students and cast a shadow on the entire education system. Restrictions have led many universities and colleges to opt for online learning to curtail the spread of Coronavirus. To overcome lockdown, online education became the primary pathway amidst technological challenges. Teachers had possibly more to do than the students and those teachers who were technologically confronted had their limits tested. The students on the other hand, had myriad challenges to face. The current study draws on the experiences of teachers and students to the introduction of online learning method during the pandemic. Qualitative research methods were utilised to answer the research questions. The study recruited students in the age of 18-25 and teachers in the age of 35-60 years through social media platforms. Informed consent was obtained, and thereafter the respondents were interviewed via telephone (NAPSWI, 2015). The study additionally utilised and analysed open discussions content of National Association of Professional Social Workers in India (NAPSWI) webinars relevant to online teaching and their experiences.

Keywords: Teaching; COVID-19; Technology; Lockdown; Online Classes; Student-Teacher Experiences; India

\footnotetext{
${ }^{+}$PhD scholar at School of Social Work, University of Delhi.

${ }^{*}$ Corresponding Author, Email: irtifamsw@gmail.com

${ }^{¥}$ Associate Professor, Department of Social Work, Bhim Rao Ambedkar College, the University of Delhi, India Email: richachoudhary2004@gmail.com

(C) 2020 Mukhter \& Chowdhary. This is an Open Access article distributed under the terms of the Creative Commons Attribution License (http://creativecommons.org/licenses/by/2.0), which permits unrestricted use, distribution, and reproduction in any medium, provided the original work is properly cited.
} 


\section{Introduction}

The college years that a student spends with peers and in lecture theatres are pivotal for scholastic development. Literature suggests that face to face peer interactions and relationships assist academic attainment (Kristiansen et al., 2019). Throughout the world, more flexible environments for learning are being created (Kemp \& Grieve, 2014). While the COVID-19 pandemic spread remains the reason for nearly 190 countries to have accepted to close their schools and colleges, affecting more than 1.5 billion children and youth, it seems that closures have impacted nearly $87.6 \%$ of the world's total enrolled learners (UNESCO, 2020). Throughout the world, the attempt was to avoid the COVID19 spread and as such the governments had national lockdowns and social distancing initiatives (Petappadan, 2020). In much of the western world, online learning has become a way to acquire skills for a large portion of student populations (Kemp \& Grieve, 2014). India's measures to limit the spread of COVID-19 has brought about some simultaneous strategies such as preparing the universities and colleges for online teaching and bring them in line with tertiary educational institutions across the world in teaching activities (Ali, 2020). These limitations led many universities and higher education institutes to opt for online learning to restrain the spread of this deadly virus. The outbreak of the COVID-19 pandemic and social distancing requirements has presented undue challenges on all educational institutions to go online, as they have to work in time restrictions and with limited resources. However, there is uncertainty and disagreement about how and what to teach, ways and means of factoring the workload of teachers and students, the teaching environment, and the implications for education equity (Ali, 2020). Higher Education Institutions need to have basic Information and Communication Technology (ICT) infrastructure to roll out online learning effectively. Staff need ICT tools and access to applications and learning platforms, as well as knowledge and capacity to use the ICT tools effectively to offer lessons in such a mode (Ali, 2020). Teacher's concern for vulnerable students is one of the most stressful aspects of their jobs right now. Teachers can see some students do not possess laptops and are used to do their readings and referencing work in the libraries and write their assignments in the computer laboratories. Some students come from families where there is only one desktop computer with parents and siblings competing for time. These identified inequities, teachers perceive that support is really required to build up student learning. Teachers are concerned about effectively engaging students through remote learning and professional collaborations (Sokal et al., 2020). The current research is an attempt to study the experiences of the teachers and students in India who are involved in online teaching-learning during COVID-19 induced lockdown period.

In our present study, we surveyed the experiences of teachers and students as an online learning method of teaching was introduced during the pandemic. The study concerned itself with challenges faced by the students during learning from home and their views on continuity of Online classes. Similarly, our concerns with the teaching community were to elicit their views online teaching and their perceptions of student learning. Following the above introduction, we offer a brief review of relevant literature and present our methodology and discuss the findings of this quick study and conclude with a discussion.

\section{Review of Literature}

The term online teaching means teaching with the help of digital technology. The purpose of our study is to explore the online teachinglearning process during this pandemic and the impacts of digital technology on its stakeholders, that is, students and teachers. A previous international study conducted by Rapanta et al., (2020) exploring the online teaching-learning process during this pandemic and impacts of digital technology served as a model for us. The scholars found that in the Covid-19 emergency situation, teachers have almost turned overnight, into both designers and tutors, using 
tools which few have fluently mastered (Rapanta et al., 2020). Educational institutions that have followed the UGC guidelines set for the smooth functioning of online teaching demonstrated that effective teaching and examination strategies during COVID-19 school restrictions and timely feedback from students had enhanced student learning (George, 2020). This study has stressed the need for understanding activities and strategies to be undertaken postpandemic, ensure the continuity of online learning (George, 2020). Kemp \& Grieve (2014) sought to understand the psychology of students regarding their preferences for learning modes versus academic outcomes. This study found that there were no differences in academic outcomes in face-to-face and online teaching; however, students enjoyed the convenience of online activities but still preferred face-to-face teaching for discussions. In evaluating the effectiveness of the online learning, one study conducted by Dhawan (2020) analyses the Strengths, Weaknesses, Opportunities, \& Challenges (SWOC) of e-learning modes in the time of COVID-19 crisis. He found that students are forced to take online learning, and some students are not comfortable with the online learning due to a lot of reasons like unavailability of internet services and smartphones or computers, high internet costs, or poor exposure to online learning experiences etc. Yet another study examined the COVID-19 school closurerelated changes and impacts on the professional development of school teachers and correlated to improved practices in their planning, teaching, and workload management (Kaden, 2020). The study found that educational stakeholders need support in developing transformed instructional models and encouraged teachers to learn new educational practices for the future. Kapasia et al. (2020), in his study, aims to identify the learning status, mode of learning, and problems related to study during this lockdown amidst the COVID-19 pandemic. This study suggests targeted interventions to create a positive space for study among students from the most vulnerable sections of society. Strategies are urgently needed to build a resilient education system in the state that will ensure to develop the skill for employability and the productivity of the young minds.

To summarise the above findings of the literature, teaching through technology demands mastery in it and preparation regarding how to teach through online mode, what strategies to be utilised. In India, the situation is more or less same with ambiguity about the online teaching as there is lack of technology and most students are from rural areas, so it is an enormous challenge for the government and educational institutions to streamline the online education system. The need for developing guidelines and standing operation procedures for proper training to all stakeholders about digital technology and how to deal with vulnerable sections online during the pandemic is of utmost priority. The outbreak of COVID-19 is an unprecedented situation which cannot be avoided, so having online classes at this point is new learning with many grudges. However, knowledge and education need to maintain continuity.

\section{Methodology}

The purpose of this exploratory study is around issues and concerns about the introduction of online teaching during COVID-19 in India. We have utilised the methodology of opportunistic or emergent sampling. This is considered to be flexible research and sampling design that allows us in qualitative research when we are still exploring (Cohen \& Crabtree. 2006). We began with a similar question to both teachers and students. The participants were selected according to their online experiences in the field of teaching and conducting online classes. The study recruited both teachers aged $35-60$ years and students aged 18-25 years from different colleges and universities in India. The purpose of the study was explained to the participants, and informed consent was obtained (NAPSWI, Code of Ethics,2015). The interviews were conducted in English amongst social work postgraduate students. After obtaining their contact, the suggestive interview guide was sent to the participants through email prior to the interview (Figure 1). Limited content analysis of open 
discussions by experts and teachers through NAPSWI (National Association of Professional Social Workers in India) has informed the authors in this undertaking. In order to ensure the anonymity of the participants the students were designated as Teachers as $A 1, A 2, A 3$ and A4, and the teachers as Students as B1, B2, B3 and B4.

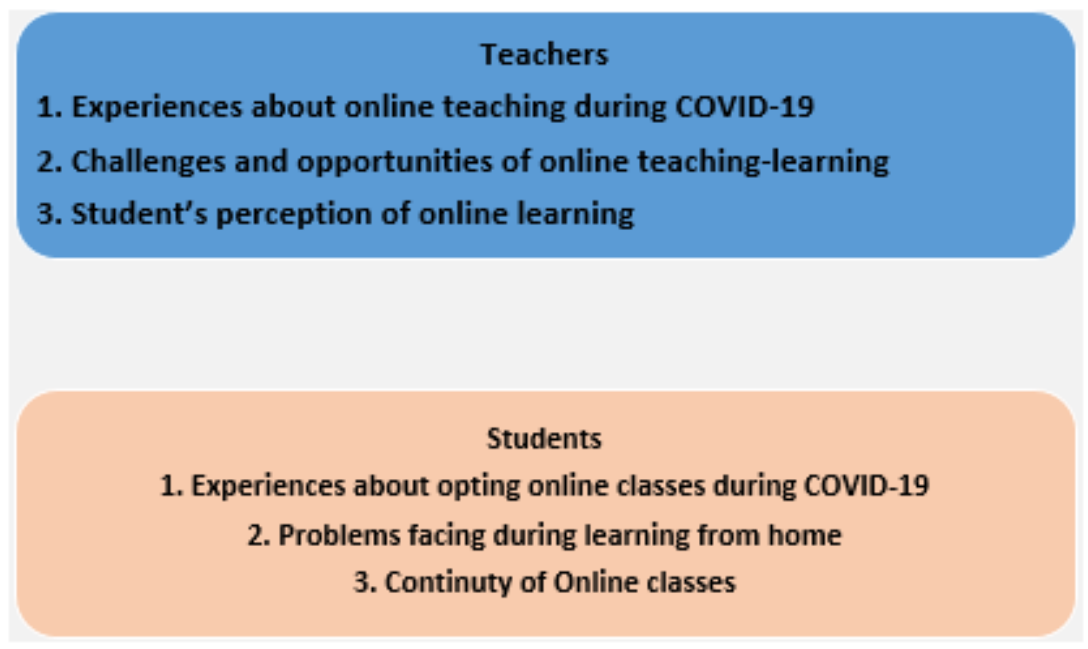

Figure 1:Experience of Students and Teachers: Relevant Areas Source: Authors

\section{Findings}

The findings of this study are presented under the following three themes for teachers and student separately as Part 1 (A) experience about online teaching-learning during COVID-19; (B) challenges and opportunities of online teaching-learning; (C) students' perception of online learning; The choice of questions for both teachers and students was based on online education and teacher-student experiences.

\section{Part: I}

\section{A. Experiences of teachers about the online teaching methodology}

The teachers have responded to the following four sub-themes. They pertain to network issues- i.e. technical (beyond the students and teachers influence) infrastructural and issues relating to the conduct of the online teaching itself (Figure 2).

\section{Network issue:}

It is a great time, I am enjoying teaching during the (pandemic) however there are many issues such as scheduling time with students that is, having network issues, slow internet services, the demand of high-cost data package which students are also unable to afford Being a social work faculty, we have to deal with fieldwork - face to face activity, which is seriously affected by this pandemic (Teacher A1).

\section{Inclusiveness:}

Interaction remained useful for teachers and students in this pandemic. The digital platform provides interaction between different students' besides belonging to any corner of the country. It is not based on any particular classroom interaction, here students culture and caste hardly matters (Teacher A2). 


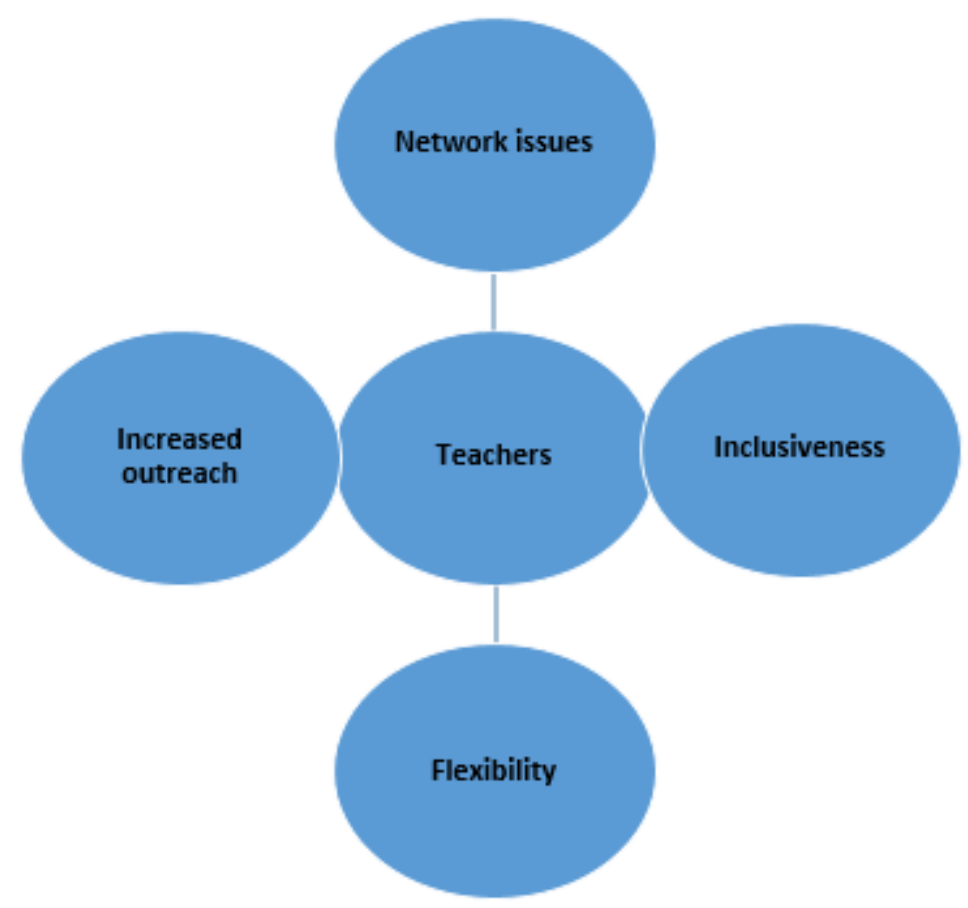

Figure 2: Experiences of Teachers about the Online Teaching Methodology Source: Authors

\section{Increased Outreach:}

As it was innovative and interactive, I felt it was a gift while dealing with students during this pandemic. Students thought it should continue after the pandemic. In India, educational institutes have different curriculum, but during online education, it does not matter, that is, teacher from north India can teach students of southern India as well. Apart from that both teachers and students miss each other's face to face communication, somehow 'real to reel' interaction with students is possibly the only sore point (Teacher A3).

\section{Flexibility:}

It is unique and also provided enough information regarding subject matters. It also provided teachers to impart technology usage and necessary flexibility to students (Teacher A4).

\section{B. Challenges and Opportunities of Online Teaching-learning during COVID-19:}

The teachers have responded to the following four sub-themes. They pertain to network issues, that is, technical, infrastructural and others relating to the conduct of the online teaching itself (Figure 3).

\section{Lack of Direct communication:}

Making materials in advance was a good thing, but missing face to face communication and dealing with their doubts was difficult (Teacher A1)

\section{Time Management Issues:}

Forming a classroom situation at home is very challenging as living in a family and behaving like a teacher who is having interaction with students. Shifting from one session to the other and returning back to parental duties is exceptionally challenging. A positive point that there is time limit in offline class, only 40 minutes are allowed to have a lecture, but in online it can go beyond an hour (Teacher A2).

\section{Challenges with Digital Infrastructure:}

During this pandemic, it was difficult to stay indoors and provide online teaching. We are still looking for digital demonstration and some training for this semester, and it is a challenging curriculum in many ways. Many platforms like Google Meeting, Zoom, etc. as students are connecting from everywhere, including public spaces - besides it is also not possible for everyone to have a digital platform so, it is challenging (Teacher A3). 


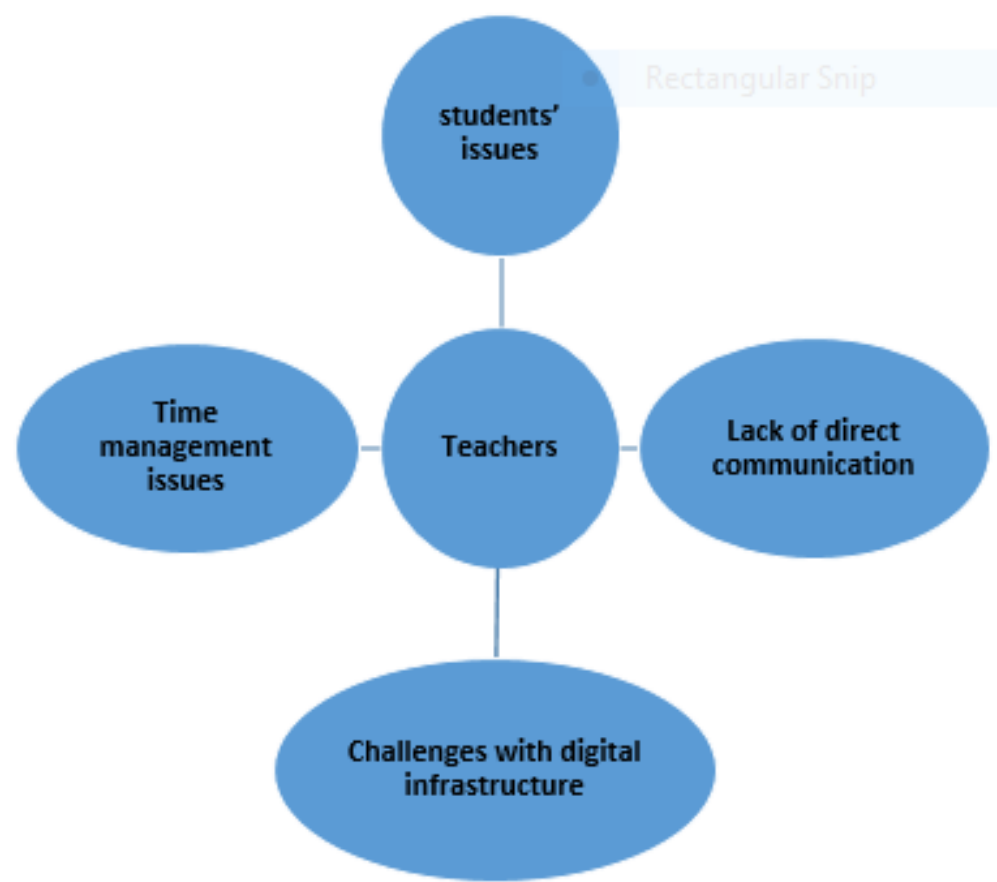

Figure 3: Challenges and Opportunities of Online Teaching-learning during COVID-19 Source: Authors

\section{Students' Issues:}

We have to learn to deal with uncertainty, during the teaching-learning process, we should take their issues and concerns and be encouraging. Some of their concerns can be tackled as part of the early interaction with the students before getting into the class topic. Simple issues such as some schedule to inform about class timings, tips to do assignments and others. This pandemic, allowed us to understand students' problems, issues and also to try to solve them. This approach must be followed once when we were in offline mode also (Teacher A4).

\section{Students' Perception of Online Learning:}

Under this theme, there are for sub-themes (Figure 4).

\section{Lack of Interest:}

Maximum students miss the face to face learning that is, classroom environment and peer group interaction. Hence it did not look very popular with them. Most of our colleagues complained that did students did not appear focused in classroom environment (Teacher A1).

\section{Challenges with Digital Infrastructure:}

Some students do not have fundamental gadgets. Mobile phone, Wi-Fi connection, high-speed data, etc.) to join class digitally (Teacher A2).

\section{Flexibility:}

Online learning is very flexible. However, there was a limited way of finding feedback. But certainly, it is a very suitable approach during this pandemic (Teacher A3).

\section{High Internet Cost:}

Majority of the students have desired that such facilities should be provided for free or at a very nominal cost. Students would prefer face to face traditional method as they are not able to meet the cost (Teacher A4). 


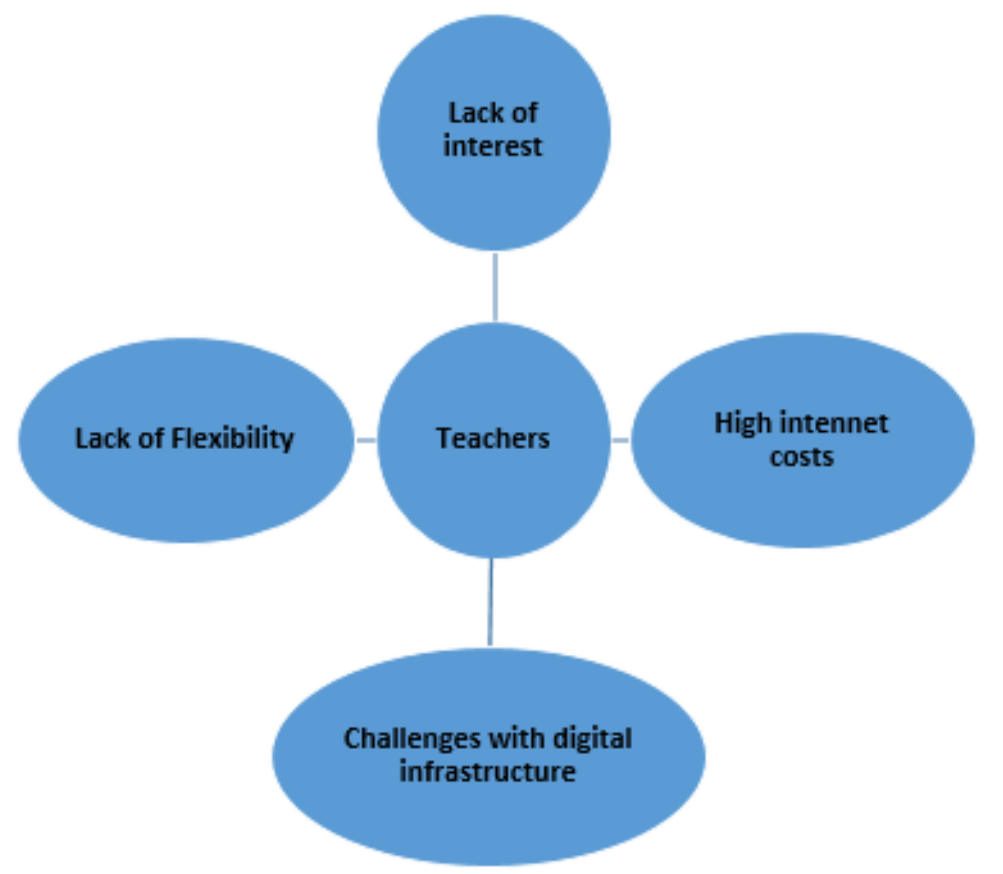

Figure 4: Students' Perception of Online Teaching Source: Authors

Part-II Experiences of students about the online teaching methodology

As said previously, the interview guide utilised for teachers and -students had similar lead questions. The findings are presented under the following three themes- Part II (A) experience about online teaching-learning during COVID-19; (B). Issues and Concerns learning from home: and (C) Continuity of online class-needs further thought

\section{A. Experiences about opting online classes during COVID-19:}

Under this theme, there are two positive outcomes to report (Figure 5).

\section{Time and cost effective}

Initially, it looked to us that we (students) had become the most significant casualties of coronavirus. Our colleges have been shut down just to prevent the spread of the virus and online classes which is a very new notion began. The various applications like zoom, google meet and google classroom etc. began supporting students and teachers in teaching and learning process (Student B1).
Attending an online class was much more comfortable than offline for a student as he can stay far away from the college. Students in urban areas have high-speed internet connectivity which neve is disappointing. So overall online classes saved half of our time which would go on the road travelling from home to college and even saved our pocket money (Student B1).

\section{Better outcomes:}

Learning in a home environment is different from the classroom, but everyone right now is trying out different ways to make it work for them. Some teachers share coursework by email. Others guide students to go through websites for self-paced learning. Still, others are conducting face-to-face classes on online meeting platforms, such as Zoom. Even extracurricular activities such as ballet, music and physical education classes are suddenly now conducted online. Just to be regular with the studies even if it is online or virtual classes to get to know more about our future lessons and related contents further (Student B3). 


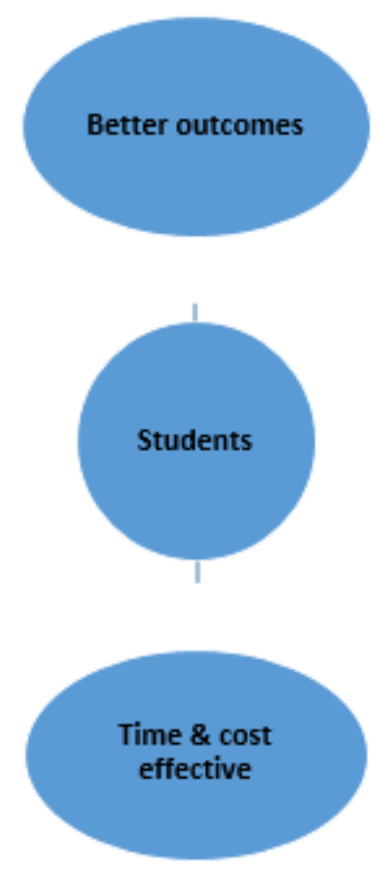

Figure 5: Experiences about Opting Online Classes during COVID-19 Source: Authors

A. Due to this pandemic, we went online. Thus, bringing to us to a new way for learning. Nobody is snooping on us and possibly watching as they do in our classrooms. Opting is not a consideration, but it is necessary for our learning and I am sure we will like this eLearning mode much more. So online classes are the only way out during this pandemic, and clearly, this is our new standard. Online classes are saving time only (Student B4).

\section{B. Issues and Concerns learning from home:}

Under this theme, there are four sub-themes, the students addressed issues and concerns with regards to lack of privacy, lack of classroom structure of the class room and the advantages that would have gone with structured settings.

\section{Lack of Privacy}

Learning from home is kind is also boring for students as there is no direct engagement with teachers and our classmates irrespective of the quality of teaching. Physical space and privacy are issues at home. (Student B1)

\section{Clear Absence of Classroom Environment:}

The hustle and bustle of classroom learning are absent- mainly, our interactions are absent.
Learning from home can be lonely for our peers. We do feel strongly isolated. (Student B2)

\section{Decreased Access to Study Material:}

Many problems like connectivity issues, especially when it rains, Strain on the eyes and absence of break which were non issues during offline classes. Lack of study material-because we do not have access to college library. So, gathering study material fills the mobile phone memory spaces and it becomes a heavy task to search on the internet and gather information which is useful. Productivity issues are also there, like sometimes students are late as well as sometimes teachers' find difficulty in connecting them (Student B3).

\section{Lack of Internet Connectivity:}

The main issue that we students face during the online class is the connectivity problem. We face a lot of buffering issues due to low connectivity depending on our residing areas. Secondly, online classes are not very interactive (Student B4).

\section{Continuity of Online Class-needs Further Thought}

Under this theme, there are four sub-themes are as under: 


\section{Addressing Students' Concern:}

If online classes are to continue, student want teachers to repeat the chapters whenever they miss their class. Or find ways by which those lessons are stored. We are lonely. Upset and are not interacting. Our mental health should be of concern to the teachers. They need to support us emotionally and mentally (Student B1).

Another issue for us is that it is tough to maintain concentration at home. We have no ways of clearing doubts. We cannot sit through before the computer or mobile phone for such a long time. Our attention span is challenged (Student B2).

\section{Home-based Learning:}

Difficulties for us to make our online learning interactive. There are few opportunities to raise questions and get clarifications (Student B2).

Online classes are going very well. However, due to significant network problems, if you in areas where there is limited connectivity, we lose, and we cannot go out due to areas where students could not opt online learning (Student B3).

\section{Discussion}

This study is intended to provide some insights on the relatively sudden introduction of online teaching during COVID-19 in India and provide a bird's eye view of the teacher-students experiences. We recognise the limitations of this concise opportunistic research. Challenge of Covid 19 and need to maintain social distancing brought the opportunities of online education to all. Teachers and students were are both involved in teaching-learning processes during this pandemic, and it is both challenging as well as an opportunity to understand digital platforms for learning. It is a very convenient way to keep students and teachers involved and ensure that the education systems continue even during this adversity. The pandemic demanded social distancing measures to stop the spread of COVID-19, so the Indian Government decided to conduct online classes to allow students to continue with their studies. Online classes have been interactive, but this has depended on teachers making it interesting for students, whilst others only do it as for recording purpose- simply to accomplish the syllabus. Online classes provide better learning opportunities for students; however, the findings suggest that there have been times that students cannot understand everything in these classes, so they fail in their assignments which might otherwise have been easy in a face to face setup. This is a new experience as some students have never used two-way video conferencing for studying. Apart from the right side of using online teaching methods, there are some challenges such as network issues, linguistic barriers, less physical participation and others, which often make students and teachers feel bored and lazy. In turn, the online classes turn uninteresting and resulting in a lack of concentration. Many times, one cannot join the online classes due to network issues as many live-in areas with a poor connection. As we know, being exposed to a screen for a long time can be challenging for us. Issues of digital learning and visual teaching are leading to health issues for those students from economically more impoverished backgrounds. The affordability of internet connections and gadgets such as laptops and uninterrupted power supply are significant issues that these students are confronted with, and the educational planers need to think of resource allocations in this sector. Educational institutions and government agencies need to create a mechanism to provide some financial relief to those students who cannot afford the internet costs in order to keep the education system accessible for all. The institutions need to make the online learning more flexible by sharing the study materials with the students on time and allocating some sessional time towards Questions and Answers (Q\& A) and clarifications twice or thrice a week. As of now, both teachers and students are facing challenges concerning the online mode of delivery of information and imparting of the skills. In online teaching-learning processes, it will be really helpful if they can have the recorded videos of the lectures on YouTube and other online platforms because this will help students to a great extent in not missing any 
classes and allow them to stay in track with the lessons even when they have network problems.

The present study suggests that there is a need to analyse the experiences of online teaching and their challenges, and the opportunities of the teacher-learning process during COVID-19 in more detail and on a larger scale. The findings of the present study have implications for future research studies in highlighting the problems of online teaching and development to increase the awareness of accessibility and convenience of adopting online channels.

\section{Conclusion}

Irrespective of the pandemic with all its challenges, education is an important activity that cannot be forsaken. However, during the pandemic, there were many challenges and some new niche opportunities for the teachers and students surfaced. In India where a sizeable population is rural and has limited access to digital technology, online classes appear to be a challenging task with limited awareness amongst teachers and students

Undoubtedly the online learning methods provide better opportunities for students learning in a home environment which is different from the classroom. It appears that there is some seriousness with which online education is being taken now with cooperation following from teachers and family members of the students towards making online education meaningful to their wards. This, in turn, assists the teachers and students during the current pandemic and bridges the gap by building their knowledge. While online instruction has been appreciated in the current situation, the impacts of face to face interactions in terms of improved concentration have also been praised. Online classes offer the flexibility of place and time. One is able to watch them as they are broadcasted in real-time or watch them as a recorded session, therefore, some study participants have requested to have online education even beyond the current pandemic.

It is amply evident in the Indian context that the teachers and students faced many challenges due to online education, particularly for timings, internet speeds, and infrastructure during the current pandemic. Our suggestion amongst the others discussed above includes further investments in online teaching technologies by universities, and also investments are required in the professional development of teachers.

\section{References}

Ali, W. (2020). Online and Remote Learning in Higher Education Institutes: A Necessity in light of COVID-19 Pandemic. Higher Education, 10(3). 16-25.

Cohen D, Crabtree B (2006). Qualitative Research Guidelines Project. July 2006.

http://www.qualres.org/HomeOppo-3815.html

Dhawan, S. (2020). Online Learning. Educational Technology Systems, 49(1), 5-22.

George, M. L. (2020). Effective Teaching and Examination Strategies for Undergraduate Learning During COVID-19 School Restrictions. Journal of Educational Technology Systems, 49(1), 23-48.

Kaden, U. (2020). COVID-19 School ClosureRelated Changes to the Professional Life of a K12 Teacher. Education Sciences, 10(6), 165.

Kapasia, N., Paul, P., Roy, A., Saha, J., Zaveri, A., Mallick, R.., ... \& Chouhan, P. (2020). Impact of lockdown on learning status of undergraduate and postgraduate students during COVID-19 pandemic in West Bengal, India. Children and Youth Services Review, 116, 105194.

Kemp, N., \& Grieve, R. (2014). Face-to-face or face-to-screen? Undergraduates' opinions and test performance in classroom vs. online learning. Frontiers in Psychology, 5, 1278.

Kristiansen, S., Burner, T., \& Johnsen, B (2019). Face-to-face promotive interaction leading to successful cooperative learning: $A$ review study. Cogent Education, 6

(1), DOI: $10.1080 / 2331186 \times .2019 .1674067$

Mustafa, N. Impact of the 2019-20 Coronavirus Pandemic on Education (Preprint) https://www.researchgate.net/publication/340 849956_Impact_of_the_201920_coronavirus_pandemic_on_education 
NAPSWI, (2015). National Association of Professional Social Workers in India, Code of Ethics, Page 9,

https://www.napswi.org/pdf/NAPSWI_Code_of _Ethics).pdf

Petappadan, B.S. (2020). Coronavirus | Lockdown, social distancing measures can't continue forever: Harsh Vardhan. The Hindu.

Retrieved from https://www.thehindu.com/news/national/soci al-distancing-measures-cant-continue-foreversays-union-health-minister-harshvardhan/article31531956.ece.

Rapanta, C., Botturi, L., Goodyear, P., Guàrdia, L., \& Koole, M. (2020). Online University Teaching During and After the Covid-19 Crisis: Refocusing Teacher Presence and Learning Activity. Postdigital Science and Education. https://doi.org/10.1007/s42438-020-00155-y

Sokal L. J. B. (2020, May 11). How to prevent teacher burnout during the coronavirus pandemic. The Conversation. Retrieved from https://theconversation.com/how-to-preventteacher-burnout-during-the-coronaviruspandemic-139353.

UNESCO (2020). COVID-19 Educational Disruption and Response. Unesco.org. Retrieved from, https://en.unesco.org/covid19/educationrespo nse.

\section{Acknowledgements}

The researchers are very grateful to Dr Venkat Pulla for his advice on every aspect of this small study. The authors are very grateful to $\mathrm{Dr}$ Rituparna Bhattacharyya, for her meticulous editing and advise. We are grateful to anonymous referees and to the journal for accepting this article and we have no conflict of interest to declare.
About the Authors

Irtifa Mukhter, is a PhD scholar at School of Social Work, University of Delhi. She has completed her Masters from social work department, University of Kashmir. She has also qualified both National and State Eligibility Test (NET/SET) in the subject of Social Work. Her research areas are Rural Development, Green Social Work (Socio-Economic and Environmental Implication of Solid and Liquid Waste Management) in rural Kashmir.

Dr Richa Chowdhary, is Associate Professor, Department of Social Work, Bhim Rao Ambedkar College, the University of Delhi, India. Dr Richa lectures social work students. Her research areas are mental health, social psychology, drug and alcohol issues, ageing and homeless children. She has five textbooks to her credit in both Hindi and English language in the field of social psychology, psychology and psychological process, group work, drug and alcohol abuse and methods of social work. She is an active member of the National Association of Professional Social Workers in Indi (NAPSWI).

\section{Author Contribution Statement}

Irtifa Mukhter, as the corresponding author of the article, confirms that I have worked on this article under advice from my mentor Dr Richa Chowdhary and I am responsible for methodology, conducting interviews, review of the literature and also the findings.

Dr Richa Chowdhary (second author) was responsible for advice transcription, assistance with first draft and discussion on findings. 